\title{
Imaginário urbano e conjuntura no Rio de Janeiro
}

\author{
Urban imaginary and conjuncture in Rio de Janeiro
}

Brasilmar Ferreira Nunes ${ }^{[0]}$, Heitor Vianna Moura ${ }^{[b]}$

[a] Doutor em Sociologia pela Université de Picardie Jules Verne (UPJV), França, professor titular da Universidade de Brasília (UnB) no Programa de Pós-Graduação em Sociologia (PPGSOL), pesquisador do CNPq e da Faperj, Rio de Janeiro, RJ Brasil, e-mail: bnunes@unb.br

[b] Mestrando do Programa de Pós-Graduação em Sociologia da Universidade de São Paulo (USP), São Paulo, SP - Brasil, e-mail: heitorvianna@hotmail.com

\section{Resumo}

A Região Metropolitana do Rio de Janeiro vem atravessando conjuntura favorável, inclusive por ter sido a escolhida para sediar grandes eventos globais nos próximos anos. A metrópole polariza região rica em recursos naturais (petróleo), e recebe vultosos investimentos industriais e em infraestrutura urbana que alterarão sua lógica espacial. Somam-se a essa conjuntura as políticas de segurança pública, que alteram o paradigma de metrópole violenta que a caracterizou nessas últimas décadas. 0 presente artigo - com caráter de ensaio - problematiza essa conjuntura. 0 pressuposto é que, em razão desses fatores, a imagem da metrópole vem se modificando positivamente. Metodologicamente, a tratamos primeiro como um fenômeno macrossocial e, posteriormente, refletimos sobre seus problemas intraurbanos estruturais que interferem no imaginário que se tem sobre ela. Teoricamente fizemos uso de estudos históricos, demográficos, econômicos e sociais cuja síntese auxilia na construção de interpretações sobre a realidade metropolitana hoje e subsidiam as reflexões apresentadas.

Palavras-chave: Rio de Janeiro. Evolução demográfica. Economia urbana. Política urbana. Cultura urbana.

\section{Abstract}

The Metropolitan Region of Rio de Janeiro goes through favorable situation including has been chosen to host global events in the coming years. The metropolis polarizes a region rich in natural resources (oil) and is also receiving substantial industrial investments and in urban infrastructure that will change her spatial logic. It is also added the security policies that is changing the paradigm of violent metropolis characterized in recent decades. This article - with character test - is trying to discuss this conjuncture. The premise is that, because of these factors, the image of the metropolis has been changing in a positive way. Methodologically, we first take 
the city into consideration like a macrosocial phenomena and after we reflect about its intraurban structural problems that interfere in the imaginary people have about it. Theoretically, we use historical, demographic, economic and social studies whose synthesis give us the support in the construction of interpretations about the metropolitan reality today and provide us the subsidies in the reflections presented here

Keywords: : Rio de Janeiro. Demographic trends. The urban economy. The urban policy. The urban culture.

\section{Introduzindo a questão}

Nosso intuito é elaborar um recorte analítico sobre a cidade do Rio de Janeiro (RJ) e sua região metropolitana (RMRJ) numa perspectiva bidimensional. Por um lado, procuramos considerar a cidade como uma totalidade portadora de uma dimensão simbólica própria. A cidade será então tratada a partir de uma perspectiva abrangente, utilizando da representação que ela detém e que faz dela uma das principais metrópoles brasileiras e continental. Nesse nível, o que está em questão é a cidade lida como um bloco "homogêneo" com sua dinâmica demográfica, econômica e cultural. Por outro lado, tentaremos perceber o seu interior, captando problemas que se repetem ao longo de sua história caracterizando em diferentes situações não apenas a cidade do Rio de Janeiro, mas também a sua região metropolitana: periferização, violência etc. questões que na cidade dão-lhe uma imagem particular. Nesse segundo nível, está em questão a heterogeneidade de seus processos sociais, físicos e culturais, cujo tratamento tem relação estreita com diferentes instâncias do poder público e a cidade.

Tratar a cidade como um todo e posteriormente entrar nas suas particularidades, procurando perceber os fenômenos que acontecem na cidade, nos parece um enfoque pertinente. Esse percurso analítico permitirá delinear, para além de aspectos negativos, os impactos de fenômenos conjunturais positivos atuais que podem ser capitalizados a seu favor. Com tal objetivo, escolhemos as dimensões populacional e econômica que exprimem a importância da cidade e de sua região metropolitana tanto para sedimentar uma imagem como para apontar rumos que possam vir a ser percorridos pelo RJ.

\section{Antecedentes históricos e aspectos atuais da cidade do RJ}

A cidade do Rio de Janeiro foi capital do Brasil durante quase dois séculos (1793-1960), quando garantiu quatro modelos de capitalidade ${ }^{1}$ : Capital da Colônia, Capital do Reino Unido, Capital Imperial e Capital Republicana, vivenciando nesses momentos transformações urbanas, umas mais, outras menos, significativas. Historiadores salientam que só podemos falar em capitalidade quando um centro urbano apresenta condições de influenciar um determinado espaço inserido num Estado; nesses casos, a cidade apresentaria capacidade de estruturar e estabelecer hierarquias no interior do território que ela polariza; a análise dessa capitalidade teria que articular a rede sobre a qual o centro urbano se articula à sua periferia numa lógica hierárquica (BICALHO, 2003).

Veremos a seguir que o Rio de Janeiro ocupa importante posição, seja na hierarquia da rede urbana brasileira, seja na polarização de população e de atividades econômicas. Essa posição certamente tem relação com a função de capital que exerceu, sobretudo ao longo dos séculos XIX e XX. Desde a transferência da capital do vice-reinado de Salvador da Bahia para o Rio de Janeiro em 1793, consolida-se o caráter central que a cidade vinha assumindo como cabeça e lócus articulador dos vastos domínios portugueses na América. Em 1808, como resultado de dinâmicas políticas na Europa envolvendo Portugal, a cidade se tornaria Corte e Capital da monarquia e do império português, trazendo-lhe visibilidade plena decorrente da súbita importância política que adquiriu, ou seja, caso único da primeira capital extraeuropeia de uma monarquia ocidental.

\footnotetext{
1 A condição de ex-capital do Brasil, sua "capitalidade", definida por Giulio Argan como a "capacidade e função de representar a unidade e síntese da nação" (FREITAG, 2009; MOTTA, 2004).
} 
Como consequência desse ato real, a cidade assumiu a essência de sua condição de capital. Em 1960, deixou de ser a capital do Brasil República, mantendo a função de capital do Estado da Guanabara até 1975, quando houve a fusão com o antigo Estado do Rio de Janeiro, tornando-se capital do atual Estado homônimo. Por outro lado, a sua base produtiva sofre os impactos dessas alterações políticas, assim como das crises que o Brasil atravessa na segunda metade do século XX, acentuados com a perda da condição de capital da República.

Desde sua fundação em 1565, a cidade do Rio de Janeiro passou por diferentes processos de intervenção em seu espaço físico. Particularmente, o governo Pereira Passos, no início do século XX (1901 a 1906), deu início a grandes reformas urbanísticas que marcam o seu ingresso na modernidade. Uma gestão polêmica que redefine o sentido de capital exercido pela cidade, provocando grandes transformações no espaço urbano de então. Com Pereira Passos, a cidade absorveu a lógica da reforma urbana, paradigma da modernidade, caracterizando diferentes governos locais, a maioria apenas fazendo uso de um imaginário obreirista, com consequências sobre a dinâmica territorial da cidade. Assim, seja na produção do território pelo aterramento de mangues e faixas litorâneas para abertura de avenidas, seja pela derrubada de morros ampliando territórios urbanizáveis, ou a abertura de túneis, construção de pontes e grandes estruturas para dar lugar a grandes avenidas, o fato é que historicamente a cidade vem sendo sempre alvo de grandes obras urbanísticas. Ou seja, diante das dificuldades técnicas, que a engenharia e a arquitetura tiveram que resolver em conjunto, a cidade sempre enfrentou desafios em sua urbanização (PINHEIRO, 2010).

Nesta virada para o século XXI, há projetos de vulto sendo implementados ou em fase de elaboração para futura implementação, muitos respondendo a exigências das agências coordenadoras dos grandes eventos previstos: (Conferência Internacional da Juventude promovida pela Igreja Católica [2013], a Copa do Mundo da FIFA [2014], os Jogos Olímpicos [2016], entre outros). Além disso, a cidade polariza região onde ocorrem fenômenos com fortes impactos econômicos, tais como a descoberta de novas reservas petrolíferas na sua costa marítima e investimentos industriais em municípios de sua Região metropolitana. Por outro lado, há ainda o controle pela ordem pública nas favelas da cidade até então nas mãos dos grupos armados do tráfego de drogas; isso faz que a cidade e a sua região metropolitana atravesse período de expectativas positivas, ao lado de algumas características que permanecem, como a capacidade de atrair correntes migratórias e seu peso relativo na representação simbólica da sociedade brasileira.

Com base nesses aspectos gerais, nos deteremos nas dinâmicas demográficas, econômica e cultural discernindo algumas implicações apontadas pela atual conjuntura.

\section{Dinâmica demográfica}

A dinâmica demográfica quando analisada em relação à rede urbana reflete a importância de determinado centro urbano. Considerando dinâmicas distintas, o seu ritmo tem forte indutor na esfera econômica (e no emprego), qualificando o processo de urbanização. No caso brasileiro, os estudos demográficos apontam que uma das características marcantes do processo de urbanização ao longo do período 1930-1980 foi a concentração progressiva da população urbana em cidades cada vez maiores; em geral nossos centros industriais mais importantes. As causas desse processo são consensuais entre os demógrafos: um forte crescimento populacional que alimentava o fluxo migratório oriundo de áreas rurais, assim como o crescimento vegetativo da população residente em cidades.

Como resultado, a distribuição da população brasileira entre municípios classificados por tamanho nos últimos 60 anos aponta que quanto mais elevada a população, mais elevados são os indicadores de crescimento populacional. Ou seja, os menores municípios do país (com até 2.000 habitantes) praticamente permanecem estáveis na participação na população total ao longo dos 60 anos censitários: de uma participação nula em 1950, alcança $0,03 \%$ em 1960, e 0,1\% em 2010. Em contrapartida, aqueles municípios com mais de 100.001 habitantes foram os que mais participaram no total da população brasileira, com destaque para os que apresentam mais de 500.000 habitantes. Estes contribuíam com 9,85\% da população brasileira em 1950 e alcançam em 2010 o percentual 
de $29,29 \%$ do total, praticamente triplicando sua contribuição para o total de população urbana em 60 anos, numa clara indicação de que se vivencia nas últimas décadas forte concentração populacional nas grandes cidades e nas nossas metrópoles (MARTINE; McGRANHAHAN, 2010, p. 16).

A Tabela 1 apresenta a distribuição da população brasileira por tamanho da população municipal nos anos censitários de 1950 a 2010, permitindo visualizar a tendência de fortalecimento dos núcleos com mais de 100 mil habitantes - contribuíam com 20,80\% da população urbana do país em 1950, alcançando em 2010 o marco de 54,75\%. Se tomarmos as cidades com mais de 500 mil habitantes, o fenômeno se repete, embora com crescimentos relativos um pouco menores no fim do período. 0 último censo de 2010 conferiu importância ao conjunto da rede urbana brasileira, destacando as capitais regionais, em especial do Nordeste, Norte e Centro-oeste, as cidades médias e as aglomerações urbanas não metropolitanas no Sul e Sudeste, indicando diluição e fortalecimento da tendência à concentração urbana da população brasileira.

Observando atentamente o fenômeno, outros aspectos se destacam. Por exemplo, entre as 11 regiões metropolitanas (RM) brasileiras em 2010, todas tiveram redução relativa nas taxas de crescimento populacional considerando a década de 1990 e a de 2000. Entre 1991 e 2000, dentre as
11 RM observadas, sete cresceram mais de 20\%: destaque para Brasília (DF) e Belém (PA), que cresceram ambas 28\% nesse período; Curitiba (PR), que aumentou sua população em 32\%; e Goiânia (G0), com crescimento de 33\%. As outras quatro RM cresceram mais de $10 \%$. Entretanto, na década seguinte, ou seja, entre 2000-2010, apenas duas RM atingiram crescimento de $25 \%$ (DF e Goiânia), cinco cresceram entre $10 \%$ e $20 \%$ e duas não atingiram $10 \%$, a saber, as RM do Rio de Janeiro (7\%) e de Porto Alegre (6\%).

No cômputo geral da distribuição da população brasileira pelas áreas metropolitanas (Tabela 2), passamos de três pontos percentuais acima do crescimento brasileiro para meio ponto abaixo ${ }^{2}$.

Esta quase estabilidade da participação das regiões metropolitanas na população total do país se manifesta de forma distinta, quer consideremos o município núcleo, quer suas periferias. Para os núcleos, temos um decréscimo nas taxas de crescimento (de 1,36 para 1,1), enquanto que nas periferias, o fenômeno é inverso, de 2,79 para 3,68. Isso indica que a urbanização das duas últimas décadas do século XX se caracterizou por forte crescimento das periferias metropolitanas, fenômeno que deve ter se repetido na década seguinte (Tabela 3). Em outras palavras, nossa metropolização ainda continua se caracterizando pela "urbanização da pobreza" (SANTOS, 1982), pois, no geral, os municípios

Tabela 1 - Distribuição da população brasileira por tamanho da população do Municíio de 1950 a 2010

\begin{tabular}{lccccccl}
\hline & $\mathbf{1 9 5 0}$ & $\mathbf{1 9 6 0}$ & $\mathbf{1 9 7 0}$ & $\mathbf{1 9 8 0}$ & $\mathbf{1 9 9 1}$ & $\mathbf{2 0 0 0}$ & $\mathbf{2 0 1 0}$ \\
\cline { 2 - 7 } Até 2.000 & \multicolumn{1}{c}{0} & 0,03 & 0,1 & 0,07 & 0,06 & \multicolumn{1}{l}{0,1} & 0,1 \\
De 2.001 a 5.000 & 0,51 & 1,41 & 2,34 & 1,84 & 1,67 & 2,55 & 2,19 \\
De 5.001 a 10.000 & 5,12 & 6,87 & 8,22 & 5,84 & 5,23 & 5,53 & 4,48 \\
De 10.001 a 20.000 & 17,28 & 17,15 & 17,36 & 13,16 & 12,56 & 11,59 & 10,35 \\
De 20.001 a 50.000 & 40,16 & 33,44 & 26,45 & 22,06 & 19,06 & 16,92 & 16,43 \\
De 50.001 a 100.000 & 16,14 & 13,41 & 11,05 & 13,16 & 13,19 & 12,33 & 11,7 \\
De 100.001 a 500.000 & 10,95 & 12,91 & 15,46 & 19,51 & 21,83 & 23,34 & 25,46 \\
Mais de 500.000 & 9,85 & 14,78 & 19,03 & 24,37 & 26,39 & 27,64 & 29,29 \\
\hline
\end{tabular}

Fonte: INSITIUTO BRASIIEERO DE GEOGRAFIA E ESTATIISTICA - IBGE, 2010.

\footnotetext{
2 De fato, o ganho de população de cidades de porte médio ou as metrópoles regionais indicam que vivenciamos um processo de "desconcentração concentrada" da população pela sua rede urbana.
} 
Tabela 2 - Taxa de crescimento populacional das Áreas Metropolitanas do Brasil (1991, 2000, 2010)

\begin{tabular}{llccccc}
\hline & & \multicolumn{3}{c}{ População Total } & \multicolumn{3}{c}{ Taxa de crescimento } \\
\cline { 3 - 6 } Sigla & Área metropolitana & $\mathbf{1 9 9 1}$ & $\mathbf{2 0 0 0}$ & $\mathbf{2 0 1 0}$ & $\mathbf{1 9 9 1} / \mathbf{2 0 0 0}$ & $\mathbf{2 0 0 0} / \mathbf{2 0 1 0}$ \\
BA & AM de Salvador - Bahía & 2.496 .521 & 3.021 .572 & 3.458 .571 & $21 \%$ & $14 \%$ \\
CE & AM de Fortaleza - Ceará & 2.401 .878 & 2.984 .689 & 3.530 .942 & $24 \%$ & $18 \%$ \\
DF & Região Integrada de Desenvolvimento do D.F e Entorno & 1.601 .094 & 2.051 .146 & 2.570 .160 & $28 \%$ & $25 \%$ \\
GO & AM de Goiânia - Goí́s & 1.230 .445 & 1.639 .516 & 2.052 .896 & $33 \%$ & $25 \%$ \\
MG & AM de Belo Horizonte - Minas Gerais & 3.515 .542 & 4.349 .425 & 4.874 .042 & $23 \%$ & $12 \%$ \\
PA & AM de Belém - Pará & 1.401 .305 & 1.795 .536 & 2.042 .417 & $28 \%$ & $13 \%$ \\
PE & AM de Recife - Pernambuco & 2.919 .979 & 3.337 .565 & 3.690 .547 & $14 \%$ & $10 \%$ \\
PR & AM de Curitiba - Paraná & 2.061 .531 & 2.726 .556 & 3.129 .269 & $32 \%$ & $14 \%$ \\
RJ & AM do Rio de Janeiro - Rio de Janeiro & 9.814 .574 & 10.894 .156 & 11.703 .788 & $11 \%$ & $7 \%$ \\
RS & AM de Porto Alegre - Rio Grande do Sul & 3.230 .732 & 3.718 .778 & 3.958 .985 & $15 \%$ & $6 \%$ \\
SP & AM de São Paulo - São Paulo & 15.444 .941 & 17.878 .703 & 19.683 .975 & $15 \%$ & $10 \%$ \\
& Total & 46.118 .542 & 54.397 .642 & 60.695 .592 & $18 \%$ & $11,50 \%$ \\
Brasil & & 146.917 .459 & 169.590 .693 & 190.755 .799 & $15 \%$ & $12 \%$ \\
\hline
\end{tabular}

Fonte: INSIITUTO DE PESQUISA ECONOMICA APLICADA - IPEA, 2010.

das periferias metropolitanas brasileiras são carentes em qualidade de vida urbana ${ }^{3}$.

A partir desses dados, podemos considerar que a urbanização brasileira se faz por um movimento duplo: de um lado, diluição de pequenos núcleos pelo território; de outro, maciça concentração da população nos maiores centros que são aqueles com mais capacidade de atração, sobretudo pelo potencial de empregabilidade.

Para a RMRJ, os dados apontam que dos 6.879.183 habitantes em 1970 ela alcança em 2000, 10.894.156 habitantes, totalizando $11.703 .788 \mathrm{em}$ 2010. Dados sobre sua dinâmica populacional, considerando o seu núcleo central e a sua periferia são também reveladores do padrão desse crescimento. Para a área central da região metropolitana, a taxa de crescimento populacional entre 1970 e 1980 foi 1,82 , enquanto sua periferia crescia 3,39 ; entre 1980 e 1991, as taxas observadas no núcleo foram de 0,67 e da periferia foi de 1,49 e finalmente, entre 1991 e 2000 , o núcleo cresce 0,74 e sua periferia 1,66 (BAERINGER, 2010) ${ }^{4}$. Esse ritmo de mudança nas taxas demográficas coincide com o fim de "milagre econômico" na segunda metade dos anos 1970, a década perdida de 1980 e o início de superação da forte crise econômica já na década de 1990.

Esses dados demográficos nos mostram que o Rio de Janeiro e sua região metropolitana guardam relativa capacidade de atração de população, indicando que, apesar de ter deixado de ser capital política do país, permanece, cinquenta anos depois, como segunda metrópole nacional. Ainda que o ritmo de crescimento do município sede da região metropolitana apresente taxas inferiores às da sua periferia, ele é ainda positivo, mesmo levando em conta o reordenamento da população por todo o território nacional observado nas ultimas décadas.

Outro aspecto que merece destaque é a capacidade de atração de fluxos migratórios pelas grandes cidades do país que tem garantido estabilidade ao longo do tempo, mesmo se certas conjunturas alterem por períodos curtos as dinâmicas históricas. Isso se deve, especialmente, às atividades econômicas que nelas se

\footnotetext{
3 Até o momento, não estão disponíveis os dados desagregados para o Censo de 2010, porém consideramos aqui que as tendências observadas se mantêm.

4 Não se tem ainda acesso aos dados desagregados das Regiões Metropolitanas para 2010.
} 
Tabela 3 - Crescimento absoluto e relativo das regiões metropolitanas e outras aglomeraç̃oes urbanas, Brasil década de 1980 e 1990

\begin{tabular}{|c|c|c|c|c|}
\hline \multirow[t]{2}{*}{ Tipo de Grande Concentração Urbana } & \multicolumn{2}{|c|}{ Taxa de Crescimento Anual } & \multicolumn{2}{|c|}{$\begin{array}{l}\text { Incremento absoluto } \\
\text { (em 000s) }\end{array}$} \\
\hline & $1980-1991$ & $1991-2000$ & $1980-1991$ & $1991-2000$ \\
\hline Regiöes Metropolitanas (8) & 2,0 & 1,99 & 8387 & 8290 \\
\hline Núcleos das RMs & 1,36 & 1,1 & 3612 & 2693 \\
\hline Periferia das RMs & 2,79 & 3,68 & 4775 & 5597 \\
\hline Outras aglomeraç̃oes metropolitanas (17) & 3,31 & 2,79 & 3942 & 3675 \\
\hline Outras aglomeracõos nõo metropolitanas (35) & 3,21 & 2,33 & 4367 & 3435 \\
\hline
\end{tabular}

Fonte: Fundação IBGE apud BAENINGER, 2010; TORRES, 2002.

implantam e que não são facilmente desativadas em razão de crises esporádicas, caracterizando relativa estabilidade nas taxas de crescimento populacional. Isso faz com que o papel ocupado por elas, tanto na distribuição da população, quanto na geração de riquezas, seja relativamente estável.

\section{Dinâmica econômica e centralidade espacial do Rio de Janeiro}

Estudos sobre a hierarquia da rede urbana brasileira nas duas últimas décadas indicam que as posições de nossas principais metrópoles no ranking nacional se mantêm praticamente inalteradas. Tomemos dois desses trabalhos: os estudos do IBGERegic $(2008)^{5}$ e do Ipea/Unicamp.IE.Nesur/IBGE (1999) ${ }^{6}$ e vejamos como se situa a RMRJ em ambos.

0 Regic aplica uma metodologia que evidencia a organização da rede urbana, suas centralidades e áreas de influência dos centros, fundamentais para o planejamento estatal e decisões quanto à localização dos investimentos em atividades econômicas de produção, consumo privado e coletivo, e implantação de serviços (públicos e privados) em bases territoriais. 0 estudo do Ipea (com uma década de antecedência), por sua vez, orientou-se pelo objetivo de proceder à análise da configuração e grandes tendências da rede urbana do Brasil, enfocando transformações no processo de urbanização e de crescimento demográfico, bem como mudanças funcionais e espaciais no sistema de cidades do país, baseado nas transformações econômicas nas décadas de 1980 e 1990. Cabe lembrar que, tanto os estudos da Regic como o trabalho do Ipea consideram a urbanização como síntese de um longo processo de mudança territorial no país, induzido pela dinâmica de localização das atividades econômicas.

Comparando os dois estudos, podemos concluir que a posição dos principais centros urbanos do país pouco se alterou nas últimas décadas. Se contrapusermos o Regic de 2008 ao trabalho realizado pelo Ipea em 1999, ambos terminam por apontar posições similares entre as grandes cidades do Brasil ${ }^{7}$. Ou seja, a capacidade de polarização da rede urbana nacional é um fenômeno que mantém certa estabilidade, no curto e médio prazo e se apoia em processos econômicos gerais que fornecem a base para sua sustentação. São processos amplos, de natureza macroeconômica e que mantêm tendências no curto e médio prazo, que se alimentam de dinâmicas regionais específicas auxiliando as tendências de

\footnotetext{
5 A sigla Regic se refere aos estudos desenvolvidos pelo IBGE para a identificação das Regiões de Influência das cidades, tendo o mais recente sido divulgado em outubro de 2008 (IBGE, 2008).

6 O Ipea publicou em conjunto com a Unicamp-IE e IBGE-Nesur estudo sobre a caracterização e tendências da rede urbana do Brasil, enfocando as transformações no processo de urbanização e no processo de crescimento demográfico (Ipea/Unicamp.IE.Nesur/ IBGE, 1999).

7 Apesar de metodologias diferenciadas, nosso interesse na contraposição de um e outro estudo é observar o resultado no que se refere ao ranking das metrópoles no quadro nacional.
} 
transformações na rede urbana das macrorregiões do país. Em ambos os estudos, São Paulo se destaca como a principal metrópole, seguida pelo Rio de Janeiro; na série histórica da Regic, o Rio de Janeiro domina a segunda posição, agora dividindo essa posição com Brasília ${ }^{8}$.

Cabe ressaltar que a industrialização brasileira a partir da década de 1970 e, particularmente, nas últimas décadas, atravessou mudanças quando lidas regionalmente. A desconcentração das unidades industriais, então baseadas no centro-sul, deve ser lida como resultado de estratégias territoriais de desenvolvimento ${ }^{9}$ que repetiram nas metrópoles regionais a lógica antes observada para o país, ou seja, priorizaram certos centros urbanos em cada região. Assim, se antes tínhamos uma economia centralizada no Sudeste (São Paulo, Rio de janeiro e Belo Horizonte), as demais metrópoles regionais passaram também a sediar unidades industriais.

Mesmo com esse processo de desconcentração concentrada da indústria no território nacional, as políticas industriais adotadas para as macrorregiões tiveram no Rio de Janeiro alguns importantes projetos $^{10}$, embora a participação relativa do município no total da produção industrial do país tenha se reduzido proporcionalmente em face das taxas observadas em outros estados da federação (Ipea/ Unicamp.IE.Nesur/IBGE, 1999, p. 366). Neste estudo o Rio de Janeiro, juntamente com São Paulo, pela sua inserção no sistema mundial de cidades, é tratado como metrópole global. Vale insistir nesse aspecto, pois uma vez que nossa indústria se abre para o exterior no início dos anos 1990, nossa rede urbana redefine suas inter-relações a partir da capacidade que detém de se articular globalmente. Significa, portanto, que "no limite, os vários sistemas nacionais tendem a se transformar em um único sistema em escala mundial" e que, no nosso caso, vem sendo comandado por São Paulo ${ }^{11}$.

Portanto, se antes a hierarquia de cidades no Brasil se fazia através de nossa rede interna e da importância de seus respectivos centros no cenário nacional, cada vez mais o que passa a ter peso é a posição da cidade no cenário internacional e seus diversos sistemas nacionais ${ }^{12}$. A abertura econômica dos anos 1990, a estabilização econômica por quase duas décadas e a revalorização monetária constituem elementos fundamentais para a nova inserção da economia brasileira no cenário internacional, fatos que irão impactar positivamente o território da área de influência das duas metrópoles nacionais. Ao mesmo tempo, o Rio de Janeiro forma com São Paulo um macroeixo urbano de peso, pois juntas constituem um mercado consumidor amplo e diversificado concentrando significativo volume de população e atividades econômicas.

0 estado do Rio de Janeiro apresenta o $2^{\mathrm{o}}$ maior PIB do país, riqueza de aproximadamente 154 bilhões de reais, sendo a atividade de serviços a preponderante (75\% do total). Destaca-se aí a posição do município do Rio de Janeiro, que ocupa o primeiro lugar no ranking estadual, sendo a administração pública mais importante - 20,2\% do valor agregado de serviços do município em 2008. Destacam-se ainda comércio e serviços de transporte e armazenagem (7,3\%); e os serviços prestados às empresas $(8,4 \%)$. Assim, apesar de flutuações ligeiras na participação municipal na formação do PIB estadual (70,5\% em 2007 e 67,8\% em 2008), a geração de riqueza continua fortemente polarizada pelo município do Rio de Janeiro e sua região metropolitana, mesmo com o ganho de importância da zona petrolífera de Campos/Macaé

8 Sem menosprezar sua importância, a posição de Brasília, certamente, é beneficiada pela ênfase que a pesquisa dá à função de gestão federal do território.

9 A sigla Regic se refere aos estudos desenvolvidos pelo IBGE para a identificação das Regiões de Influência das cidades, tendo o mais recente sido divulgado em outubro de 2008 (IBGE, 2008).

${ }^{10}$ Notadamente no período da ampliação da refinaria de Duque de Caxias, a modernização do Porto do Rio de Janeiro e a construção da Usina Atômica de Angra dos Reis, além do incentivo à indústria naval.

11 O Rio de Janeiro aparece como um centro de segunda ordem ao lado de Buenos Aires e Cidade do México na América Latina, Johannesburgo na África, Hong Kong, Manilha, Bancoc e Seul na Ásia (Ipea, 1999, p. 362).

${ }^{12}$ Como veremos à frente, a escolha do Rio de Janeiro para sediar grandes eventos internacionais insere a cidade de forma ativa no circuito das grandes metrópoles mundiais. 
no norte do estado, que não ameaça essa hegemonia (SEPLAG/CEPERJ, 2010) ${ }^{13}$.

Essa composição do PIB estadual e a participação da região metropolitana impactam o mercado de trabalho. Os dados apontam que 53\% dos empregos formais ali estão alocados no setor serviços que somados aos $19 \%$ no comércio contabilizam $72 \%$ do emprego formal no "setor terciário". A indústria é responsável por 19\% do emprego formal, participação essa que deverá se alterar em anos próximos, pois há grandes investimentos sendo implantados no estado e na sua região metropolitana (siderúrgicas, indústrias do ramo petrolífero, naval, automobilístico etc.) fazendo do Rio de Janeiro e sua região metropolitana importante polo econômico, explicando boa parte das razões pelas quais sua população cresce.

\section{O potencial de polarização da RMRJ}

A atual inserção da economia brasileira na dinâmica global, o principal foco de dinamismo para as metrópoles, se baseia na produção e comercialização de comodities, entre as quais predominam atividades terciárias beneficiárias da integração global (Ipea/Unicamp.IE.Nesur/IBGE, 1999). Nas metrópoles (São Paulo e Rio de Janeiro, sobretudo) se instalam os núcleos decisórios dos maiores grupos econômicos com negócios no país, sendo prioritárias inclusive para sediar seus centros de pesqui$\mathrm{sa}^{14}$. No ranking das 500 maiores empresas do país da revista EXAME para 2008, por exemplo, entre as dez maiores, cinco têm sede no Rio de Janeiro, uma posição de destaque que se mantém historicamente há décadas ${ }^{15}$ (EXAME, 2008). As duas metrópoles são priorizadas nas decisões locacionais de indústrias intensiva em tecnologia e serviços típicos de cidades mundiais, tais como telemática, pesquisa e desenvolvimento (P\&D), consultoria de negócios, gestão empresarial e financeira e serviços de transportes internacionais e indústria criativa.

Por outro lado, uma importante fonte de geração de emprego e renda no mundo globalizado é o turismo. Trata-se de um setor cuja modernização, ao contrário de outros, induz o crescimento do emprego (direto e indireto), o que o torna estratégico nas políticas de incentivo ao emprego, sobretudo urbano. Para o caso brasileiro, o Rio de Janeiro é o segundo maior destino do turismo nacional e internacional (MINISTÉRIO DO TURISMO, 2011), favorecendo políticas voltadas para o setor na cidade.

A sociedade metropolitana fluminense se caracteriza ainda pela presença de uma burocracia que mesmo com a transferência da capital para Brasília ainda faz da cidade um importante núcleo burocrático, além de uma cultura popular com elevado potencial de criatividade. São esferas distintas que, no conjunto, alimentam dimensões do capital simbólico da cidade. Esse capital simbólico disputa espaço na representação da nação facilitado pelas redes de TV e de mídia em geral presentes na cidade.

Dada a conformação física do sítio da cidade (montanhas, praias, florestas) e a sua dinâmica de ocupação, temos um ambiente que aproxima fisicamente o pobre, a classe média e o rico, gerando um cotidiano peculiar. Essa convivência na cidade gera tensões é claro, mas também produz novas sociabilidades que terminam por definir o "modo de ser" carioca. As tentativas de ultrapassar a visão dualista da sociedade local, resquício de uma sociologia dos anos 1960 , se refletem na consciência que o carioca de classe média ou alta está adquirindo sobre o abandono das políticas públicas sofrido pelas favelas ao longo de décadas.

\footnotetext{
${ }^{13}$ No ranking dos cinco mais importantes centros terciários do estado do Rio de Janeiro, além do município capital aparecem em ordem de importância Duque de Caxias, Niterói, São Gonçalo e Nova Iguaçu, todos na RMRJ.

${ }^{14}$ No Rio de Janeiro encontra-se cerca de 19\% das cinquenta maiores empresas estatais, empregando cerca de 30\% dos trabalhadores dessas empresas (por exemplo, Petrobras, Petrobras Distribuidora, Embratel, Furnas, BNDES etc.).

${ }^{15}$ Sua importância global é atestada em um estudo publicado e produzido em 2010 na e pela renomada revista Foreign Policy sobre as cidades globais. São Paulo e Rio de Janeiro são as únicas cidades brasileiras que figuram no ranking com 66 cidades, ocupando, respectivamente, a $33^{\mathrm{a}}$ e a $53^{\underline{a}}$ posição. Números, que apesar do decréscimo nos últimos quatro anos, apresentam um potencial de crescimento surpreendente, uma vez que um estudo publicado e produzido pela mesma revista cita as mesmas cidades entre as 35 mais dinâmicas do mundo em 2025, respectivamente ocupand o o 4ํ e o 34ํㅡㄴ lugar (FOREIGN POLICY, 2012).
} 
Vale considerar ainda que a complexidade da vida na metrópole torna o ambiente de interação ali mais atrativo do que em centros menores. Ou seja, há uma urbanidade que qualifica a vida social nas metrópoles e seduz o indivíduo, dada a diversidade de vínculos possíveis de serem vivenciados ${ }^{16}$. Esse argumento, utilizado por Èmille Durkheim e pelos intelectuais da Escola de Chicago, como Wirth em seu ensaio "O urbanismo como modo de vida" (1983), na virada do século XIX para o século XX, é adequado para explicar certas características de nossas metrópoles. A disponibilidade de serviços coletivos (saúde, educação, habitação, lazer, e mesmo potencial de empregabilidade, dentre outros) continua colocando nossas metrópoles em posição privilegiada em comparação a cidades menores, agindo como fatores de atração que a cidade detém.

\section{E os problemas permanecem "na cidade"}

Iremos nos deter sobre as condições gerais da cidade, particularmente as características que formam parte de sua imagem negativa. Aqui o que está em questão são aspectos que atingem o morador na cidade no seu cotidiano urbano, num território com forte heterogeneidade física, social, cultural, econômica.

O espaço metropolitano do Rio de Janeiro se estruturou com uma cidade central (Rio de Janeiro), que a partir de diferentes planos urbanísticos ao longo do século XX transformou-se no símbolo da nação, tal qual a bandeira ou o hino nacional, concentrando investimentos em algumas de suas áreas tomadas como vitrine para tal propósito. Nesse sentido, a cidade teve no governo Pereira Passos (1901 a 1906) a iniciativa de grandes reformas urbanísticas que marcaram o seu ingresso na modernidade. Uma gestão polêmica que redefiniu o sentido de capital que a cidade exercia, e que provocou grandes transformações no espaço urbano. Podemos considerar que, com essa gestão, a cidade absorveu a lógica da reforma urbana que foi caracterizando seus diferentes governos, a maioria apenas fazendo uso de um imaginário obreirista, sem maiores consequências sobre a dinâmica territorial caracterizada por fortes disparidades.

Contribuíram para isso um sítio privilegiado, apropriado pelo capital imobiliário que se firmou ao longo do tempo e a presença de um setor industrial que surge a partir do século XIX e que ao longo do século XX foi se espalhando pelos seus subúrbios. Essa lógica territorial fez com que o uso do termo "subúrbio" pela população do Rio de Janeiro modificasse o sentido ao longo do processo de expansão da cidade. Entre as várias conotações que adquiriu o termo, cabe lembrar o fato de que "subúrbio" foi utilizado quase que exclusivamente para se referir a bairros ferroviários e populares; Soares (1960 apud FERNANDES, 2011, p. 35) verificou que "não se denomina subúrbio onde não há trem, mesmo que sejam áreas periféricas", com baixa densidade populacional e outras características próprias aos subúrbios em geral.

Essa expansão pela área física da cidade das unidades fabris levou junto também a classe operária que, na medida do possível, ia residindo próximo das fábricas. Tal dinâmica no século XX foi caracterizando diferentes áreas da metrópole, uma vez que diversificava tanto os padrões de moradia, comércio e infraestrutura entre os diferentes bairros, ao mesmo tempo em que diferenciava a representação da cidade entre seus habitantes ou para o conjunto do país: Zona Sul, Zona Norte, subúrbio, Baixada (e atualmente Zona Oeste) passam a servir de parâmetros para sistemas classificatórios de classe social e status, sugerindo um ethos específico de seus moradores. Se na Zona Sul da cidade a presença de um sítio urbano pleno em serviços corrobora com a noção de "modernidade", a Zona Norte e o subúrbio com sua baixada costumam ser associados ao "tradicionalismo" e ao "atraso", imagem marcada pelo discurso da privação de equipamentos urbanos e de comportamentos tidos como "exóticos" e "marginais". Segundo Carneiro (2009, p. 214), esse discurso de exclusão, "reforçado pela apatia burocrática e inépcia administrativa

16 Não se pode abstrair o fato de que "sociedade é interação social" e a densidade populacional da metrópole é ambiente favorável às interações humanas, sobretudo favorecendo a mais complexa divisão social do trabalho, contribuindo assim para processos de mobilidade e mudanças sociais. 
decorrente de políticas públicas que privilegiam sempre a Zona sul da cidade", dá suporte à relevância do local de moradia na constituição de identidade de grupos sociais na cidade.

Atualmente, a cidade se expande para onde está previsto, por exemplo, a instalação da infraestrutura dos Jogos Olímpicos, com o estoque de equipamentos coletivos que a acompanha (metrô, abertura de túneis, moderno sistema de transporte coletivo via ônibus etc. ${ }^{17}$. Esse volume de investimento vem hoje, somado ao seu processo de ocupação, fortalecendo a classificação interna que destaca e valoriza os bairros Barra da Tijuca e Recreio em detrimento de outros, tais como Bangu, Curicica, Gardênia Azul, Realengo e Paciência, mecanismo similar ao que aconteceu historicamente entre Zona Sul e Zona Norte ${ }^{18}$.

Somou-se ainda, para fortalecer esse quadro, o desgoverno de políticos locais alimentado durante décadas pelos sucessivos impasses entre o governo estadual/local e o governo federal e as disputas entre grupos do crime organizado ${ }^{19}$. Ganha visibilidade o fato de que o abandono das áreas precarizadas da cidade terminou por criar territórios vazios de poder público, o que permitiu ao crime organizado ocupar o terreno. Disso resulta que a violência urbana passou a ocupar a cena midiática cotidiana consolidando imagem negativa da metrópole tanto interna quanto externamente ${ }^{20}$. Em médio prazo, essa situação foi deteriorando a qualidade de vida para o conjunto da metrópole, acentuando fenômenos típicos das grandes cidades do chamado "terceiro mundo": periferização, favelização, violência etc. Os efeitos negativos dessa situação foram vários, e destacamos a expulsão de capitais produtivos da área, a preferência de multinacionais em instalarem escritórios e unidades fabris em São Paulo, Curitiba, Salvador etc. A RMRJ continuou ainda como o segundo polo econômico do país, porém sem o dinamismo que se observava em algumas outras capitais estaduais.

Nessa imagem violenta e negativa de décadas, teríamos que entender o porquê de o Rio de Janeiro continuar atraindo novos habitantes, particularmente os de baixa qualificação profissional $^{21}$. Fluxos migratórios são conjuntos de indivíduos à procura de inserção na lógica salarial-monetária. A possibilidade real e/ou potencial de empregabilidade na metrópole em comparação às cidades pequenas ou mesmo à área rural do Brasil são concretas. Aqui, o Rio de Janeiro detém forte poder de atração. Além disso, o acesso a serviços coletivos para parcelas da população, mesmo se qualitativamente ruins, é mais vantajoso do que o seu acesso nas áreas rurais ou de núcleos menores espalhados pelo território nacional. É importante ressaltar que a ideia de que faltam projetos sociais nas favelas não se confirma na prática. Eles são muitos e quase sempre convivem de maneira caótica. 0 que é real é a descontinuidade e fragmentação e a baixa qualidade das políticas e serviços públicos à disposição daquelas populações (sobreposição de ações, ações simultâneas não coordenadas, vazios territoriais das ações etc.) (HENRIQUES; RAMOS, 2011).

Tais aspectos nos auxiliam, por exemplo, na reflexão sobre as favelas, estigmatizadas pela violência urbana, lidas em geral como fonte dos

\footnotetext{
${ }^{17}$ Na Zona Oeste, segundo o Censo de 2000, nos anos 1990 ocorreu uma explosão de moradias em favelas na Barra da Tijuca e Jacarepaguá: em 1991 os moradores nesses assentamentos representavam 14\% da população total da região, passando para 21\% em 2000 em razão de incrementos de 70 mil pessoas (CUNHA; PEDREIRA, 2008).

${ }^{18}$ Nesse sentido, valeria uma investigação mais dedicada sobre os efeitos das políticas públicas, que em certo sentido visam inserir tal espaço urbano em uma nova configuração central da cidade, fortalecendo uma alocação simbólica de alguns de seus bairros, que os associam à zona mais abastada da cidade, a Zona Sul (CECCHETTO; FARIAS, 2009).

${ }^{19} \mathrm{O}$ estado do Rio de Janeiro e a cidade do Rio de Janeiro durante décadas sempre manteve uma relação de oposição ao governo central ou, quando não, de disputas entre o governo municipal e estadual. Só recentemente esse quadro se alterou para uma aliança entre os três níveis de governo.

${ }^{20}$ A violência urbana no Brasil é um fenômeno que alcança praticamente todas as principais cidades do país e não é privilégio do Rio de Janeiro. Apesar disso, há certa ênfase midiática sobre os fatos que ali ocorrem.

${ }^{21}$ Centramos nesse perfil de baixa qualificação, pois é aí o núcleo social de dificuldades de acesso à cidade, mesmo em condições macroeconômicas relativamente satisfatórias pelas quais o país vem atravessando nessa última década.
} 
problemas urbanos. Se na origem as favelas foram constituídas por populações "excluídas" - por diferentes razões - do acesso à cidade, hoje já são parte constitutiva da identidade local de tal maneira que é impossível imaginar o Rio de Janeiro sem suas favelas e toda a energia que dali brota e que enriquece a cultura metropolitana. Como escreve Sérgio Magalhães do IAB/RJ, refletindo sobre a conjuntura atual no Rio de Janeiro:

[...] o urbanista incorpora a diversidade espacial como valor. Não mais uma só forma urbana - a da perfeição - mas tantas quantas as condições específicas, históricas, geográficas e culturais promoverem. A multiplicidade morfológica certamente será uma riqueza das cidades (MAGALHÃES, 2012, p. 3).

Evidente que há problemas nesses ambientes de favelas, sobretudo se, como é recorrente em textos acadêmicos, as olharmos como algo exterior à cidade. Valadares (2005) argumenta sobre os dogmas que as ciências sociais utilizam para tratá-las: encará-las como fenômeno especifico dentro da cidade, visão recorrente entre geógrafos, urbanistas, juristas, demógrafos, antropólogos e sociólogos. Ou então tratá-las como lócus da pobreza, o território urbano dos pobres, sustentado nos anos 1960 pela teoria da marginalidade, simbolizando território dos problemas sociais. Ou ainda, a favela tratada como fenômeno homogêneo e não diverso como é a sua real condição, o que leva a considerá-las todas idênticas, abstraindo a historicidade de cada uma (PRETECEILLE; RIBEIRO, 1999). Esse dogmatismo obscurece a natureza heterogênea das favelas e inclusive de uma metrópole como o Rio de Janeiro onde coexistem múltiplos "modos de vida" constituindo o elemento dinâmico da vida social. Assim, a questão de fundo será tratar o universo das favelas como heterogêneo e diferenciado, seja fisicamente, seja, sobretudo, nas modalidades de organização coletiva e de constituição de um capital social que lhe é próprio, transpondo a oposição entre urbanidade e cidadania. Romper com tais perspectivas nos permitiria passar da etnografia do enclave à sociologia das culturas urbanas ${ }^{22}$.

A política de segurança pública representada pelas Unidades de Polícia Pacificadora (UPP) vem sendo a forma encontrada para intervir e combater o crime organizado que se espalhou pelas áreas faveladas do Rio de Janeiro, retomando e devolvendo essas áreas ao controle estatal, recuperando o monopólio do uso da força. São estratégias de pacificação e controle de áreas dominadas há pelo menos duas décadas por grupos criminosos organizados e armados que controlavam a rotina das favelas. Pelas UPPs se procura recuperar espaços públicos da metrópole, trazendo de volta aos elementos constitutivos de sua identidade as formas de sociabilidade geradas pelo modelo de urbanização que elas representam.

Se bem conduzida, essa política de segurança deverá alterar a lógica de regulação social em ambientes em que as regras eram ditadas por grupos paralelos; grupos estes que interferiam no funcionamento da maioria dos serviços urbanos públicos ou privados, nas relações comerciais e imobiliárias, na oferta ou regulação de esferas e bens culturais coletivos e, frequentemente, nas relações privadas entre moradores ou mesmo dentro das famílias (HENRIQUES; RAMOS, 2011).

Se tomarmos as UPPs ou, por exemplo, a localização da infraestrutura física onde ocorrerão os próximos grandes eventos, veremos que são priorizadas áreas restritas do núcleo central e parte da Zona Oeste da cidade que certamente irão valorizar esse território induzindo futuros deslocamentos da população mais pobre para as periferias ${ }^{23}$. Atuando em conjunto com o mercado imobiliário, tais políticas poderão favorecer uma dinâmica especulativa que se isoladas de reformas estruturais, tenderiam a uma "expulsão branca" dessa população, comprometendo mais ainda o "direito à cidade" para certas camadas. Assim, para os grandes eventos e a política urbana que deles advém serão necessárias flexibilidade e agilidade nos processos decisórios, ao risco de negar

\footnotetext{
${ }^{22}$ A esse respeito ver Isaac Joseph (2007): L'athlète moral et l'enquêteur modeste, conforme a bibliografia.

${ }^{23}$ A explosão do preço dos imóveis nessas áreas, tanto para venda, como para aluguel, já aponta para esta situação.
} 
a cidade enquanto espaço político em favor do marketing urbano e da "cidade espetáculo"24.

\section{Elementos conclusivos: conjuntura de euforia}

Nosso propósito foi refletir sobre a RMRJ, metrópole que, por várias razões, atravessa momento de euforia ${ }^{25}$. Palco de recentes e de futuros eventos globais, a metrópole recupera dimensões de sua histórica capitalidade, hoje dividindo essa representação com outras metrópoles do país. São três as razões que estão na base desse momento atual: a disponibilidade de recursos naturais (petróleo); a atração do fluxo de turismo nacional e internacional; e os grandes eventos internacionais previstos para os próximos anos. São dimensões com forte impacto de médio e longo prazo na economia e na sociedade metropolitana e vêm monopolizando os esforços das políticas urbanas local, estadual e federal.

0 estado do Rio de Janeiro é o principal produtor de petróleo no país e teve a sua capacidade ampliada com o "pré-sal" que explora o recurso nas plataformas marinhas. Em se tratando de energia não renovável, o petróleo atua de forma decisiva na configuração das vantagens competitivas de regiões e países (PIQUET, 2011). Nesse sentido, o estado do Rio de Janeiro se beneficia mesmo se submetido a pressões políticas para a redistribuição dos lucros de sua exploração ${ }^{26}$. Haveria a partir dos royalties da exploração, forte capacidade de investimento por parte do governo estadual; daí a importância da integração entre governo local e estadual. Atualmente, a cidade alcança, depois de décadas, essa harmonia política entre os três níveis de governo, o que vem facilitando a disponibilidade de recursos para investimentos urbanos. Essa compatibilidade política vem garantindo a implementação de projetos urbanos na região metropolitana. Além disso, a retomada da industrialização estadual por meio da implantação de novas indústrias de base e de bens duráveis com fortes efeitos multiplicadores. A implantação do Polo Siderúrgico no Distrito de Santa Cruz, filiais de multinacionais do automóvel, a ampliação do porto de Itaguaí, todos na região metropolitana, são ações com fortes impactos sobre o emprego e renda na RMRJ.

A recente realização da Conferência da ONU, RIO+20, a sede de alguns dos jogos e a final da Copa do Mundo de Futebol (2014), a escolha da cidade para sede dos Jogos Olímpicos (2016), entre outros, colocam a cidade no centro da imagem internacional do país e capitaneiam uma série de medidas de política urbana que estão alterando a paisagem tradicional da cidade. Em razão desses eventos se implantam projetos de revitalização de antigas áreas degradadas da cidade nos moldes do que aconteceu em outras metrópoles espalhadas pelo planeta; ou mesmo se amplia a oferta de infraestrutura para a expansão do sitio urbano para a região da Barra da Tijuca. Destaque-se o plano complexo de regeneração de territórios degradados na área do porto e novas áreas de expansão do tecido urbano. 0 fenômeno não é original: grandes eventos mundiais vêm, nos últimos tempos, desenvolvendo estratégias de sustentabilidade que buscam maximizar seu impacto positivo e duradouro na vida e na economia das cidades em decorrência dos fortes investimentos necessários para sua a realização ${ }^{27}$. 0 resultado para a cidade se manifesta na esfera material - redes de transporte, equipamentos de lazer e turismo, instalações esportivas etc. que se incorporam à vida da cidade - e na esfera imaterial - com efeitos são

\footnotetext{
${ }^{24}$ Processos que tiveram como principais críticos a Internacional Situacionista, cujas críticas à espetacularização urbana se destacam na obra de Guy Debord (1997), em que ele defende a participação ativa dos atores em todos os campos da vida social em detrimento da passividade dominante.

${ }^{25}$ O Rio de Janeiro é hoje uma das dez cidades mais dinâmicas do mundo segundo o mais recente Global Metro Monitor, publicação conjunta da London School of Economics e da Brookings Institution que compara o dinamismo econômico (capacidade de gerar emprego e renda) das 150 maiores metrópoles do mundo espalhadas em 53 países no período anterior à crise (1993-2007) com o do período posterior (2008-2010).

${ }^{26}$ Desde 2010 um projeto de lei visa redefinir a lógica de distribuição dos royalties entre os municípios, Estados e União, gerando um clima de instabilidade nos estados e municípios produtores, que teriam sua receita abalada caso a aprovação passasse por todas as instâncias de governo.

${ }^{27}$ Esta preocupação já era notada na década de 1960 (Jogos Olímpicos de Roma), mas se intensificou podendo ser destacados casos como os de Seul (1988), Barcelona (1992), Austrália (2000), Pequim (2008) e Londres (2012), que apontam a complexa relação entre a realização de grandes competições e a política urbana.
} 
sutis, porém importantes (domínio da cidade com base em novos conhecimentos, alteração na percepção e no comportamento diante da cidade por parte de seus habitantes etc.).

No entanto, a realização de eventos de tal porte sempre produzem impactos também negativos sobre a cidade e sua população. Podemos citar como exemplo no Rio de Janeiro: o impacto sobre populações que moram nas proximidades da "Vila Olímpica"; a demolição de casas e do centro de lazer do Morro da Providência para a construção de um teleférico focado no turismo; a especulação imobiliária e enobrecimento da Zona Portuária, alterando completamente a dinâmica nela existente; a privatização de prédios e áreas públicas a partir do Projeto para o Porto; a flexibilização das normas construtivas e ambientais em favor de grandes empreendimentos etc. São elementos que nos fazem refletir sobre a possível criação de "cenários urbanos", assentado na ideia de um processo de enobrecimento de espaços, em prejuízo de "palcos urbanos", cujos espaços se completam a partir da participação e dos usos plurais de seus frequentadores (JACQUES, 2004).

Assim, é fundamental a análise equilibrada da conjuntura da cidade: nem um inebriante exame a partir da euforia compartilhada pelos veículos de comunicação, nem condenação de toda e qualquer ação sobre a cidade, mas sim uma análise sensível às mudanças conjunturais e seus possíveis efeitos estruturais sobre a dinâmica da cidade.

Algumas dessas questões foram ressaltadas ao longo do texto e tendem a se alterar, seja na sua materialidade, seja na postura de seu tratamento por parte das administrações públicas. 0 caso exemplar é a ação sobre as áreas de favelas: urbanizar tais assentamentos envolve processo complexo/multifacetado, num trabalho entre arquitetos, governo, moradores, ambientalistas e outros profissionais.
A fundamentação urbanística dessas ações tem duplo caráter, aparentemente paradoxal: promover as condições urbanas exigidas pela contemporaneidade e o reconhecimento das preexistências ambientais e culturais (MAGALHAES, 2012) ${ }^{28}$.

Assim, são várias as lições que a experiência atual do Rio de Janeiro nos ensina. Primeiro, a importância da disponibilidade de recursos naturais estratégicos e, mais do que isso, os usos que se faz dos recursos advindos de sua exploração. Por outro lado, a entrada da cidade na disputa para sediar grandes eventos internacionais a coloca no rol das metrópoles mundiais com potencial de desenvolvimento acima da média. Isso porque tais eventos pressupõem uma série de medidas de políticas públicas que ultrapassam a oferta da infraestrutura necessária às competições. Em paralelo, são implantadas ações gerais de melhoria da acessibilidade, mobilidade, segurança etc. itens que são, em geral, precários em metrópoles da América do Sul. 0 pressuposto que une eventos esportivos e política urbana se encontra expresso na "Carta Olímpica" no seu capítulo 1, item 2 (14) que tem entre suas formulações: "Promover junto das cidades e países anfitriões o legado positivo dos Jogos Olímpicos".

Transformações e dinâmicas refletem no mapa de tendências de investimentos no estado do Rio de Janeiro entre os anos de 2012 e 2014 (FIRJAN, 2011). A Firjan apresenta não só uma prospecção de investimentos recordes no período, 211,5 bilhões de reais, mas um volume $40,2 \%$ superior de investimentos no setor de infraestrutura do triênio anterior. Totalizando R $\$ 51$ bilhões em infraestrutura, destacam-se os investimentos em transporte intraurbano ${ }^{29}$ e logística portuária ${ }^{30}$. Ao mesmo tempo, competir com outros centros urbanos do chamado primeiro mundo para sediar eventos importantes e sair vencedora traz reconhecimento

\footnotetext{
${ }^{28}$ A cidade do RJ acaba de receber o prêmio Cith Barcelona FAD Award 2012, conferido pelo governo da Catalunha e pela cidade de Barcelona pelo programa de urbanização de favelas que a cidade vem desenvolvendo desde os anos 1990. Justificando o premio o júri considera "a melhor iniciativa de melhora urbana internacional".

${ }^{29}$ Entre os principais projetos é possível citar a construção da Linha 4 do metrô (R\$ 4,2 bilhões), que ligará a Zona Sul à Barra da Tijuca e a implantação do Bus Rapid Transit - BRT (R\$2,8 bilhões), corredores exclusivos de ônibus que alimentarão os demais modais de transporte (metrô e aeroporto) (FIRJAN, 2011).

${ }^{30}$ No setor portuário, os principais investimentos são a construção do complexo Portuário do Açu (R\$ 2,7 bilhões), a expansão do Porto do Rio (R\$ 1,4 bilhão) e a construção do Porto do Sudeste (R 1,3 bilhão) para exportação de minério de ferro, em Itaguaí (FIRJAN, 2011)
} 
que alcança, em primeiro lugar, seus próprios moradores e se estende ao país. A relação do cidadão com a cidade se altera, pois, o que está em jogo é a imagem do nacional através da imagem que a cidade irá oferecer durante as competições. Mostra que na globalização a identidade nacional tem nas grandes cidades a sua melhor representação.

Não restam dúvidas de que a cidade recupera parte de sua capitalidade exercida ao longo da sua história, no entanto, só o tempo dirá se a conjuntura de euforia será capaz de gerar dinâmicas e efeitos duradouros, revelando, no longo prazo, transformações nas bases estruturais do país, em especial nas suas bases econômica e demográfica.

\section{Referências}

BAENINGER, R. (Org.). População e cidades: subsídios para o planejamento e para as políticas sociais. Campinas: Ed. da Unicamp, 2010. v. 1.

BAENINGER, R. Interiorização da migração em São Paulo: novas territorialidades e novos desafios teóricos. In: ENCONTRO NACIONAL DE ESTUDOS POPULACIONAIS, 14., 2004, Caxambu. Anais... Belo Horizonte: ABEP, 2004.

BICALHO, M. F. A Cidade e o império. 0 Rio de Janeiro no século XVIII. Rio de Janeiro: Civilização Brasileira, 2003.

CARNEIRO, S. S. Rio, zona norte e zona sul: fronteiras para além dos estigmas. In: CARNEIRO, S. S; SANT'ANNA, M. J. G. (Org.). Cidade: olhares e trajetórias. Rio de Janeiro: Garamond, 2009. p. 193-218.

CECCHETTO, F; FARIAS, P. 'Tu mora onde?' Território e produção de subjetividade no espaço urbano carioca. In: CARNEIRO, S. S.; SANT'ANNA, M. J. G. (Org.). Cidade: olhares e trajetórias. Rio de Janeiro: Garamond, 2009. p. 219-240.

CUNHA, E. M. P.; PEDREIRA, R. S. P. Como anda o Rio de Janeiro. Brasília: Ministério das Cidades, 2008.

DEBORD, G. A sociedade do espetáculo. Rio de Janeiro: Contraponto, 1997.

EXAME. As 500 maiores empresas de 2008. 2008. Disponível em: <http://pt.scribd.com/doc/16105576/ 500-Maiores-Empresas-Exame>. Acesso em 20 Dez. 2011.
FERNANDES, N. N. O rapto ideológico da categoria subúrbio: Rio de Janeiro 1858-1945. Rio de Janeiro: Apicuri, 2011.

FIRJAN. Decisão Rio 2012-2014. 2011. Disponível em: <http://www.firjan.org.br/main.jsp?lumChannelId=40 2880811F24243A011F243843420638>. Acesso em: 23 nov. 2012.

FOREIGN POLICY. The most dynamic cities of 2025. 2012. Disponível em: <http://www.foreignpolicy.com/articles/2012/08/13/the_most_dynamic_cities_of_2025>. Acesso em: 20 nov. 2012.

FREITAG, B. Capitais migrantes e poderes peregrinos: o caso do Rio de Janeiro. Rio de Janeiro: Editora Papirus, 2009.

FUNDAÇÃO CEPERJ. Produto Interno Bruto dos municípios - 2004-2008: Estado do Rio de Janeiro. Rio de Janeiro: CEPERJ, 2010.

HENRIQUES, R.; RAMOS, S. UPPs sociais: ações sociais para consolidar a pacificação. In: URANI, A; GIAMBIAGI, F. (Org.). Rio: a hora da virada. Rio de Janeiro: Elsevier, 2011.

INSTITUTO BRASILEIRO DE GEOGRAFIA E ESTATÍSTICA IBGE. Distribuição da população brasileira por tamanho da população do Município 2010. Disponível em: <http://www.sidra.ibge.gov.br/bda/tabela/listabl. asp?z=cd\&o=3\&i=P\&c=1290 >. Acesso em: 10 dez. 2011.

INSTITUTO BRASILEIRO DE GEOGRAFIA E ESTATÍSTICA IBGE. Regiões de Influência das Cidades - 2007. 2008. Disponível em: <http://www.ibge.gov.br/home/geociencias/geografia/regic.shtm>. Acesso em: 20 mar. 2012.

INSTITUTO DE PESQUISA ECONÔMICA APLICADA IPEA. Taxa de crescimento populacional das áreas metropolitanas do Brasil (1991, 2000, 2010). 2010. Disponível em: <http://www.ipeadata.gov.br>. Acesso em: 10 Dez. 2011.

INSTITUTO DE PESQUISA ECONÔMICA APLICADA - IPEA; UNIVERSIDADE ESTADUAL DE CAMPINAS - UNICAMP; INSTITUTO BRASILEIRO DE GEOGRAFIA E ESTATÍSTIC IBGE (Org.). Caracterização e tendências da rede urbana do Brasil. São Paulo: Ed. da Unicamp, 1999. v. 3.

JACQUES, P. Espetacularização urbana contemporânea. In: FERNANDES, A.; JACQUES, P. B. Territórios urbanos e políticas culturais. Salvador: Cadernos do PPGAU/ FAUFBA, 2004. p. 3-15. 
JOSEPH, I. L'athlète moral et l'enquêteur modeste. Paris: Econômica, 2007.

MAGALHÃES, S. A cidade e a imperfeição. Jornal 0 Globo, Rio de Janeiro, 2 jun. 2012. p. 3.

MARTINE, G.; MCGRANHAHAN, G. A transição urbana brasileira: trajetória, dificuldades e lições apreendidas In: BAENINGER, R. (Org.). População e cidades: subsídios para o planejamento e para as políticas sociais. Brasília: NEPO/UNICAMP, 2010. p. 11-24.

MINISTÉRIO DO TURISMO. Turismo no Brasil: 2011 2014. 2011. Disponível em: <http://www.turismo. gov.br/export/sites/default/turismo/o_ministerio/ publicacoes/downloads_publicacoes/Turismo_no Brasil_2011_-_2014_sem_margem_corte.pdf>. Acesso em: 22 mar. 2012.

MOTTA, M. Rio, cidade-capital. Rio de Janeiro: Jorge Zahar, 2004.

PINHEIRO, A. I. F. (Org.). Rio de Janeiro: cinco séculos de história e transformações urbanas. Rio de Janeiro: Casa da Palavra, 2010.

PIQUET, R. (Org.). Mar de riquezas, terras de contrastes: o Petróleo no Brasil. Rio de Janeiro: Mauad X/ FAPERJ, 2011.
PRETECEILLE, E.; RIBEIRO, L. C. Q. Tendências da segregação social em metrópoles globais e desiguais: Paris e Rio de Janeiro nos anos 80. Revista Brasileira de Ciências Sociais, v. 14 , n. 40 , 1999, p. 143-162. doi:10.1590/ S0102-69091999000200010.

SANTOS, M. Ensaios sobre a urbanização brasileira. São Paulo: Huicitec, 1982.

TORRES, H. Migration and the environment: a view from Brazilian metropolitan areas. In: HOGAN, D. J.; BERQUÓ, E.; COSTA, H. S. M. (Ed.). Population and environment in Brazil: Rio + 10. Campinas: CNPD/ABEP/NEPO, 2002. p. 22-37.

VALADARES, L. A invenção da favela: do mito de origem à favela.com. Rio de Janeiro: FGV Editora, 2005.

WIRTH, L. O urbanismo como modo de vida. In: VELHO, O. (Org.) 0 fenômeno urbano. Rio de Janeiro: Zahar, 1983. p. $90-113$.

Recebido: 18/09/2012

Received: 09/18/2012

Aprovado: 12/02/2013

Approved: 02/12/2013 